\title{
Impact of consumers' understanding of date labelling on food waste behaviour
}

\author{
Luiza Toma' ${ }^{1}$ (D) Montserrat Costa Font ${ }^{1} \cdot$ Bethan Thompson $^{2}$
}

Received: 7 June 2017 / Revised: 26 September 2017/ Accepted: 4 October 2017 /

Published online: 17 October 2017

(C) The Author(s) 2017. This article is an open access publication

\begin{abstract}
This research analyses the impact that the level of understanding of date marking (among other influences) has on the food waste behaviour of consumers in the European Union focusing on a comparison between European Union countries. The data were extracted from the Dataset Flash Eurobarometer 425: Food waste and date marking (European Commission in Flash eurobarometer 425: food waste and date marking, European Commission, Brussels, 2015) and structural equation models to estimate the strength of these influences on behaviour. The results show that socio-demographics (age; education; occupation); behavioural control (perceptions regarding the need for better and clearer information about 'best before' and 'use by' date labelling on food products; frequency of checking date labels when shopping and preparing meals); and understanding of 'best before' and 'use by' labels have significant effects on behaviours related to lower food waste (use of senses instead of labels to decide whether to eat or throw away food e.g., nonperishable foods from own kitchen cupboard with no 'best before' date indicated on the label which were not bought recently; or food products which must be used within a certain number of days after opening and are past that; and the need for 'best before' dates on non-perishable foods, such as rice, pasta, coffee or tea). The stated understanding of date labelling is a key influence in all models and explains a consistent fifth (ceteris paribus) of the variance in behaviour.
\end{abstract}

Keywords Date labelling - Food waste behaviour - Structural equation modelling $\cdot$ European consumers

Mathematic Subject Classification 91C99 • 62H99

Luiza Toma

luiza.toma@sruc.ac.uk

1 SRUC, King's Buildings, West Mains Road, Edinburgh EH9 3JG, UK

2 University of Edinburgh, King's Buildings, West Mains Road, Edinburgh EH9 3JG, UK 


\section{Introduction}

Currently, 88 million tonnes of food are wasted in the European Union (EU-28) every year. This represents $173 \mathrm{~kg}$ per capita or $20 \%$ of the EU's annual food production, and is projected to increase by $40 \%$ by 2020 if no action is taken. Over $50 \%$ of this food waste occurs at the household level (Stenmarck et al. 2016), a pattern seen across many developed regions (Gustavsson et al. 2011; Buzby et al. 2016).

The causes of food waste are complex and operate at a number of inter-related levels in the supply chain (High Level Panel of Experts (HLPE) 2014; Mena et al. 2014; Parfitt et al. 2010). Actions taken upstream in the food supply chain may affect the amount of waste produced downstream, including households. For example, manufacturers in conjunction with retailers may set expiry dates, in particular best before dates, very conservatively (Priefer et al. 2016). Evidence suggests that even small increases in shelf life could result in a significant reduction in food waste at the household level (WRAP 2013b, 2015). There are therefore valid questions about the extent of responsibility that households have for the food waste they produce or efficacy in reducing it. In particular, recent sociological research has highlighted how food waste is simply a consequence of everyday life and the constraints faced by modern households (Evans 2011, 2012). However, other research suggests that there are inter-related behaviours, over which households have control that are associated with lower levels of food waste (WRAP 2013a; Quested et al. 2013). As regards the household behaviour towards food waste, the Waste and Resources Action Programme (WRAP) monitors nine key behaviours on a regular basis which are believed to lead to lower levels of household food waste: planning meals in advance, checking levels of food in cupboards prior to shopping, making a shopping list, storing meat and cheese in appropriate packaging, storing all fruit (except bananas) in the fridge, using the freezer to extend the shelf-life of food, portioning rice and pasta, using up leftovers, and using date labels on food (Quested et al. 2013). Different types of households cite different reasons for wasting food; for example young professionals tend not to plan meals, whereas young families report being sensitive to dates and cook too much (WRAP 2007). More evidence is required to understand the antecedents of these behaviours and therefore how behaviour might be changed. This research will focus on one of these behaviours, the use of date labels on food.

The European Union (EU) labelling requirements for food products are currently specified in Regulation (EU) No 1169/2011 (European Union 2011). This regulation contains the list of mandatory food information to be included in all food labels from December 2016 onwards. The list includes the date of minimum durability or the 'use by' date. The regulation also specifies the way it shall be expressed as well as for which products it is not required such as fresh fruit, wines, alcoholic beverages, salt, sugar, etc. Most pre-packed food requires the date of minimum durability or 'best before' date and only for the case of food products with potential microbiological hazards is the 'use by' date required. Therefore, after the 'use by' date a food product shall be deemed to be unsafe in accordance with Article 14(2) to 
(5) of Regulation (EC) No 178/2002. Dissimilarly, the 'best before' date refers to quality issues distant to food safety ones.

A number of authors reported the current food date labelling system as a barrier to the management of food from both food waste and food safety perspectives (Priefer et al. 2016; Broad Leib et al. 2016; Rahelu 2009; Food Standards Agency (FSA) 2016; TNS European Behaviour Studies Consortium (EBSC) 2014). Most recently, evidence from the USA indicates that simplifying and clarifying expiry date labelling could be one of the most cost-effective ways to reduce food waste (Broad Leib et al. 2016).

This research seeks to build on these findings by analysing the extent to which knowledge of the difference between 'best before' and 'use by' dates and the frequency of date label checking affect the use of date labels on food (such as willingness to eat non-perishable foods when a best-before date is missing) across socio-demographic groups and across the Western, Eastern and Mediterranean EU28. The reason for estimating the model in these three regions is due to the fact that, while date labelling in EU countries follows food Regulation (EU) No. 1169/2011 of the European Parliament and Council, each country transitions from a different regime and the speed and type of rollout of the legislation across countries may affect the level of date labelling knowledge of their citizens. The EBSC eightcountry study (2014) found Finland and UK respondents to be more knowledgeable than those from other countries. However, no clear north-south patterns were identified. Jörissen et al. (2015) compare food waste behaviours in Italy and Germany and conclude that attitudes towards the handling of and regard for food are more influenced by social class and educational level than by nationality. In terms of linking date labelling knowledge and behaviour to food waste prevention, there are significant differences across the EU-28 (European Environment Agency 2015). As highlighted through this research, the relationship between knowledge and behaviour is affected by a range of attitudinal and social factors, and is linked to the different ways of shopping and cooking. The way country effects play out for food waste needs to be better understood (EBSC 2014) and this research attempts to add to the current evidence.

The research is structured in five sections: subsequent to the introduction, the next section describes the research hypotheses and the conceptual model, followed by the presentation of data and methods, discussion of results and conclusions.

\section{Research hypotheses and conceptual model}

To understand the influence of date label understanding on date label usage, a conceptual model (Fig. 1) was developed to describe part of the household reasoning process that supports food waste generation. Namely, it attempts to identify the influence of date marking in the decision-making process concerning food waste generation taking into account socio-demographic characteristics, understanding of date labelling and behavioural control aspects such as the perceived need for clearer information about date labelling and frequency of checking date labels. 


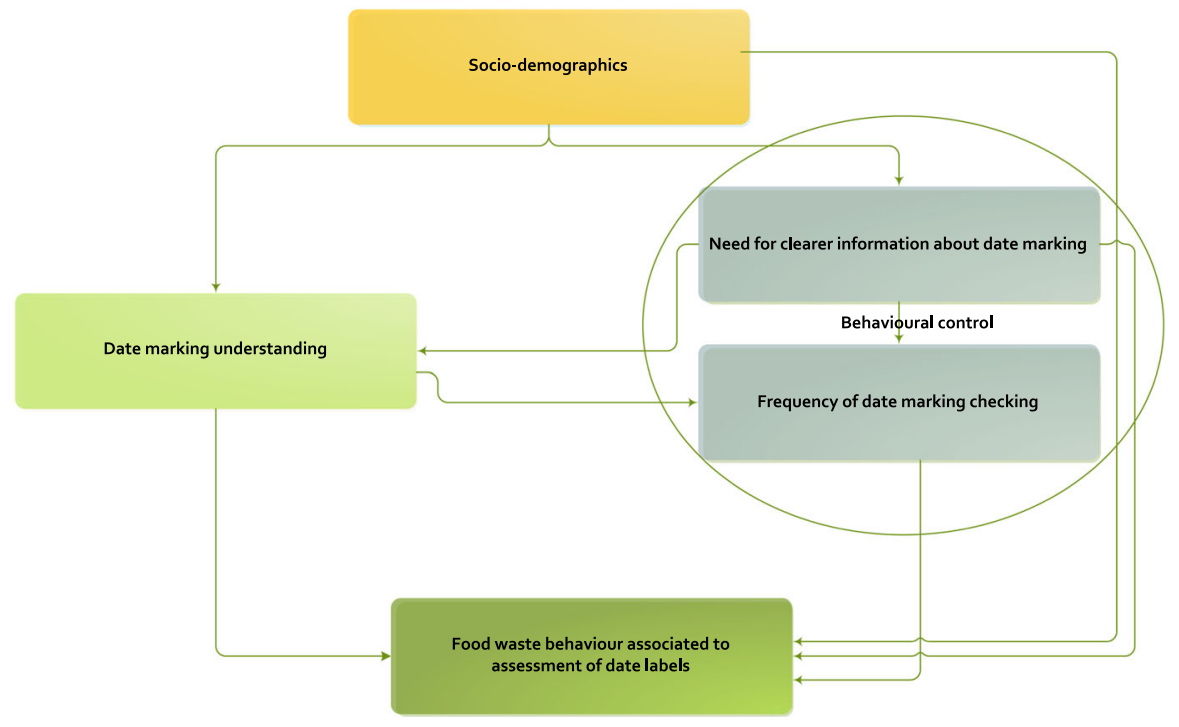

Fig. 1 Conceptual model

The conceptual model is consistent with the following research hypotheses based on findings from the food waste literature:

Hypothesis 1 Socio-demographics (age, education and occupation) have an influence on (a) date marking understanding; (b) behavioural control regarding the appropriate use of date marking; and (c) behaviours associated with lower food waste.

A number of studies have indicated that socio-demographic characteristics have an influence on knowledge and use of date labels (WRAP 2011; Broad Leib et al. 2016; EBSC 2014; van Boxstael et al. 2014). WRAP (2011) found that older respondents paid less attention to date labels than younger respondents in the UK. This may be related to the fact that older people have learnt to trust and use their senses instead of labels better than younger generations; however it may appear to be in contradiction with the established evidence regarding the stronger food safety perceptions of the adult consumers as compared to the younger ones (Sanlier 2009). Younger respondents are found to be more likely to misinterpret 'best before' date labels-believing them to be indicators of food safety and using them as a risk indicator-and thus more likely to discard food past the date on the label (Broad Leib et al. 2016). On the contrary, older respondents were more likely to misinterpret 'use by' dates-believing them to be indicators of food quality, and potentially exposing themselves to a food safety risk. This is consistent with results of other studies which found a negative relationship between the age of consumers and the amount of food waste generated (Quested et al. 2013; Van Garde and Woodburn 1987; Watson and Meah 2012; Visschers et al. 2016). A recent study of eight European countries found that young male consumers had the best knowledge 
on these issues, even though overall 'best before' dates were misinterpreted more often than not by all categories of consumers (EBSC 2014). A Belgian study found that more than two thirds of respondents knew the difference between 'best before' and 'use by' (Van Boxstael et al. 2014). They found that older respondents $(65+)$ were more familiar with date labelling overall, and in contrast to the WRAP (2011) study, 'best before' was better understood by younger respondents whereas 'use by' was best understood among the older respondents. However, it should be noted that the Belgian study only asked respondents to indicate their subjective knowledge with the question "Do you know the labels 'use by' and 'best before'?" The difference between the results of the above-mentioned studies indicates that, although socio-demographics seem to have an influence on the knowledge of and use of date labelling, there is mixed evidence about the sign of their effects.

Employment status is another socio-demographic factor found to have an impact on household food waste (WRAP 2014). Specifically, those households where the main earner was retired were less likely to throw food away when past the date on the packaging. While there is a relationship between age and retirement, employment status still had a statistically significant effect when age was controlled for.

Gender has not been found to have a significant effect on consumers' knowledge of date labels (Van Boxstael et al. 2014; WRAP 2011), though women were shown to be marginally more aware that 'use by' marking had food safety implications (no statistical significance was reported) (WRAP 2011). However, in wider food waste studies some gender differences have been observed. For example, WRAP (2014) found that more avoidable food and drink waste was reported by women in the kitchen diary measures of food waste. Mallinson et al. (2016) also found that one of the clusters ("Kitchen Evaders") reporting high levels of food waste included a high proportion of young women. This finding was supported by Visschers et al. (2016); however here the composition of the female respondent's households tended to be the driving factor. They concluded in fact that specific household situations could override strong intentions, attitudes and norms to reduce food waste.

The "Kitchen Evaders" cluster of Mallinson et al. (2016) was also the cluster with the lowest reported level of education, with the majority not having studied beyond A-level. Higher levels of education seem to be associated with waste of certain types of foods, e.g., fruits and vegetables (Visschers et al. 2016). However, it is not clear to what extent this might reflect differences in purchasing patterns.

Hypothesis 2 Date labelling understanding has an influence on frequency of use of date labels and behaviours associated with lower food waste.

Adding to the effect of socio-demographic factors on both knowledge/ understanding of date labels and use of date labels, it was also hypothesised that understanding of date marking influences the frequency of use of date labels and other behaviours associated with lower food waste.

Both WRAP (2011) and van Boxstael et al. (2014) found that understanding (objective or subjective knowledge, respectively) of date labelling does not necessarily result in correct or more frequent usage of date labelling. For example, van Boxstael et al. (2014) found that only $49.3 \%$ of their respondents took date 
labels into account when deciding whether or not to eat a food product compared to the $69.6 \%$ who reported knowing the difference between date labels. They also found significant variation by product type in the date label usage to assess edibility. Similarly, Rahelu (2009) reported that consumers do not treat different food groups in the same way. In a similar vein, WRAP (2011) found differences in the use of date labels by product type; however their analysis outlined a complex array of factors such as attitudes, values, habits, risk perception and trust, which potentially affected the relationship between knowledge and behaviour. Factors such as trust in or perceptions of labels (Broad Leib et al. 2016) as well as the role of habit and repeat purchasing (FSA 2016) are important. This may mean that, while consumers may know the difference between date labels, they might not consider it necessary to check the date label either at the point of purchase or at home since they develop a sense of how long the product lasts.

Outside the food waste literature there have been a number of studies across environmental (Kaiser and Fuhrer 2003; Redman and Redman 2014; Peschel et al. 2016), health (Wardle et al. 2000; Worsley 2002; Grunert et al. 2010) and food safety (Meysenburg et al. 2014) fields that have shown that objective or declarative knowledge is a necessary but not sufficient condition for behaviour. For example Peschel et al. (2016) found that, while less knowledge might make one less likely to make an environmentally friendly choice, better knowledge might not make one significantly more likely to choose it either as people tend to balance between factors such as price and the environment.

Kaiser and Fuhrer (2003) and Redman and Redman (2014) also found limited impact of objective or declarative knowledge alone and argued that it needed to converge with other domains of knowledge (procedural, social, and effectiveness) in order to affect behaviour.

A Food Standards Agency (FSA) (2016) survey on food labelling issues reported that consumers considered retail food labelling information in a 'needs-based behaviour' and that the most frequently checked information when purchasing food was the 'use by' or 'best before' information. However, many authors reported that the current food date labelling system with different types of date marking can generate confusion among consumers (Rahelu 2009; NRDC 2013; FSA 2016; Priefer et al. 2016). The FSA (2016) report also noted that respondents stated internal conflicts between not wishing to take health risks by ignoring date labels and not wanting to waste food.

Hypothesis 3 Perceived behavioural control (need for clearer information on date labelling and frequency of checking date labels) has an effect on behaviours associated with lower food waste.

According to Ajzen and Madden (1986) and numerous other authors, perceived behavioural control will influence behaviour directly and/or indirectly through behavioural intentions. Visschers et al. (2016) emphasised the relevance of perceived behavioural control on food waste behaviour. They found that perceived behavioural control was one of the most important predictors of the amount of food waste per household member. However, evidence from WRAP (2007, 2011) suggested that frequency of use or sensitivity to date labels was not a 
straightforward way of identifying low food wasters from high food wasters. This is because there seem to be behaviours associated with high date sensitivity (e.g., food planning and shopping) that combined may result in lower waste; equally there are behaviours associated with low date sensitivity or frequency of checking such as a willingness to eat leftovers or food past its date, which may also be associated with lower food waste (WRAP 2011). Similarly, Visschers et al. (2016) found that, with regard to consuming leftovers, consumers with more positive attitudes and norms regarding food waste reduction and with lower risk perceptions about consuming leftovers showed a higher intention to reduce food waste as well as reporting less food waste.

The behaviours related to lower food waste measured by the Flash Eurobarometer 425 (European Commission 2015) are about consuming food after or without knowing the 'best before' date or eating products after they have been open for more than the recommended number of days. It was therefore hypothesised that those who check dates most frequently, i.e., appear to be more sensitive to dates, would be less likely to exhibit the behaviours analysed.

\section{Data and methods}

\subsection{Data}

The data used in this research were extracted from the Dataset Flash Eurobarometer 425: Food waste and date marking (European Commission 2015). The Eurobarometer survey was carried out by the TNS Opinion and Social through face-to-face interviews of citizens in the 28 Member States of the European Union, with an average sample size of 950 observations.

The variables included in the analysis are:

- socio-demographic variables (age, education, occupation);

- understanding of 'best before' and 'use by' labels on food products;

- perceived need for better and clearer information on the meaning of 'best before' and 'use by' dates indicated on food labels;

- frequency of checking the 'use by' or 'best before' dates on food labels when shopping and preparing meals;

- food waste behaviour, i.e., use of senses instead of labels to decide whether to eat or throw away food (e.g., non-perishable foods from own kitchen cupboard with no 'best before' date indicated on the label which were not bought recently; or food products which must be used within a certain number of days after opening and are past that); and stated need for 'best before' dates on nonperishable foods, such as rice, pasta, coffee or tea.

Table 1 presents a description of the latent variables and the corresponding indicators included in the SEM models.

Figure 2 shows that more than half of the consumers interviewed in each of the three groups always look at 'use by' or 'best before' dates on food labels when 
Table 1 Description of latent variables and their corresponding indicators

\begin{tabular}{lll}
\hline $\begin{array}{l}\text { Latent } \\
\text { variables }\end{array}$ & Indicators (statements) & Values and labels \\
\hline
\end{tabular}

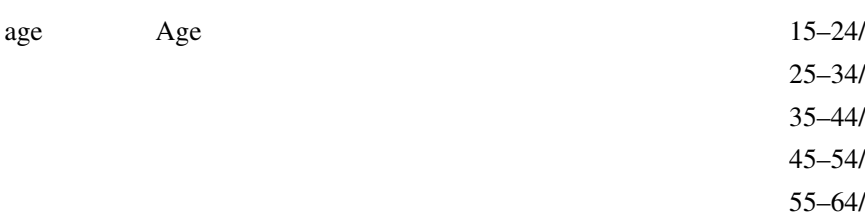

education Education

occupation Occupation

label

help

behavfr

behav home?
What do you think 'best before'/'use by' on a food product actually means?

correct answer for 'best before' is 'The food can be consumed after this date, but it may no longer be at its best quality'/correct answer for 'use by' is 'The food will be safe to eat up to this date, but should not be eaten past this date'

Do you think better and clearer information on the dates indicated on food labels would help you to waste less food at home?

Do you think better and clearer information on food product labels would help you to waste less food at

How often, if at all, do you look at 'use by' or 'best before' dates on food labels when shopping and preparing meals?

65 and older

No full time education/

Still studying/

Up to $15 /$

16-19/

20 years and older

Not working/

Manual workers/

Employees/

Self-employed

No correct answer/

One correct answer/

Two correct answers

Otherwise/

Yes

Never/

Rarely/

Sometimes/

Often/

Always

Otherwise/

'Use it anyway' or 'use it if the product looks all right and the Packaging is not damaged'

Some food labels indicate that, once opened, a product must be used within a certain number of days. If you have not used up the product within the time indicated on the label, what do you usually do?

In future, if you no longer found 'best before' dates on other non-perishable foods, such as rice, pasta, coffee or tea, how would you respond?
Otherwise/

'Use it if the product looks all right and the packaging is not damaged'

Otherwise/

'You do not need this information' 

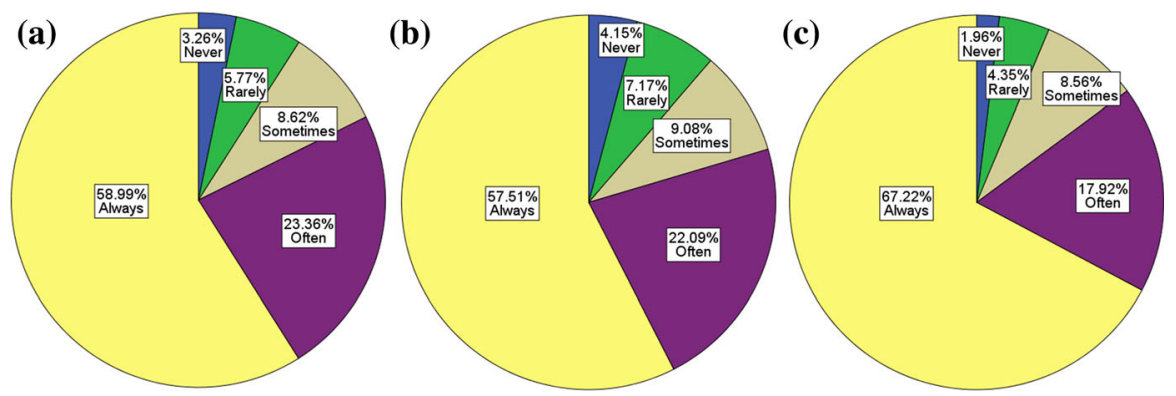

Fig. 2 a-c How often, if at all, do you look at 'use by' or 'best before' dates on food labels when shopping and preparing meals? Responses for Western, Eastern and Mediterranean subsamples

shopping and preparing meals, and a fifth up to a quarter of consumers check dates on a frequent basis. These results are in line with those reported by the FSA (2016) survey.

Regarding behaviours, Fig. 3 shows that in the absence of date labels more than $60 \%$ of respondents in each group feel confident to use their own senses to assess the safety of the product before consuming it, with Western Europeans being the most, and Mediterranean consumers the least confident.

However, in the presence of date labels and outside the period of time during which the product must be used after opening, a lower percentage of consumers choose to consume it (Fig. 4).

The same ranking as in Fig. 3 and similar differences between the three groups apply. This may indicate that Mediterranean and Eastern European consumers may be more risk-averse to food safety issues and/or less sensitive to food waste than Western Europeans.

Figure 5 shows that Mediterranean and Eastern European consumers have a stronger need for date labelling information than Western Europeans in order to perform their food consumption decisions (the same ranking as for the previous two
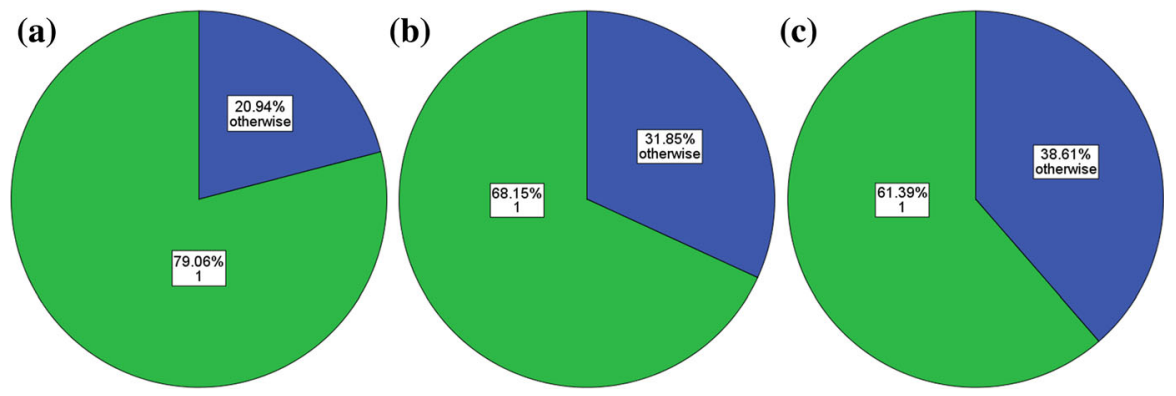

Fig. 3 a-c If you found a package of spaghetti in your kitchen cupboard with no 'best before' date indicated on the label and you could not remember when you bought it, what would you do? ('use it anyway' or 'use it if the product looks all right and the packaging is not damaged'). Responses for Western, Eastern and Mediterranean subsamples 

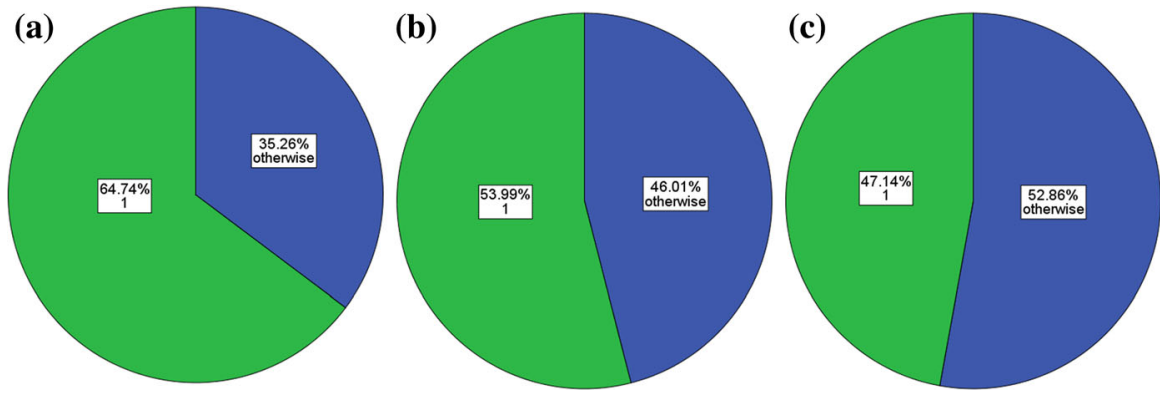

Fig. 4 a-c Some food labels indicate that, once opened, a product must be used within a certain number of days. If you have not used up the product within the time indicated on the label, what do you usually do? ('use it if the product looks all right and the packaging is not damaged'). Responses for Western, Eastern and Mediterranean subsamples

behaviours applies; however a much higher difference is shown between the groups).

The aforementioned statistics may indicate a lower tendency to generating food waste as a result of date labelling evaluation in Western Europe as compared to Eastern and Mediterranean Europe.

\subsection{Methods}

Structural equation models (SEM) with observed and latent variables were used to estimate the influence of these determinants on stated food waste behaviour in three groups of countries-Western Europe (France, Belgium, Netherlands, Germany, Luxemburg, Denmark, Ireland, Great Britain, Finland, Sweden, Austria), Eastern Europe (Czech Rep, Estonia, Hungary, Latvia, Lithuania, Poland, Slovakia, Slovenia, Bulgaria, Romania, Croatia) and Mediterranean Europe (Italy, Greece, Spain, Portugal, Cyprus, Malta).

As each variable might influence behaviour and intentions both directly and indirectly (through their effect on other variables in the model, which subsequently
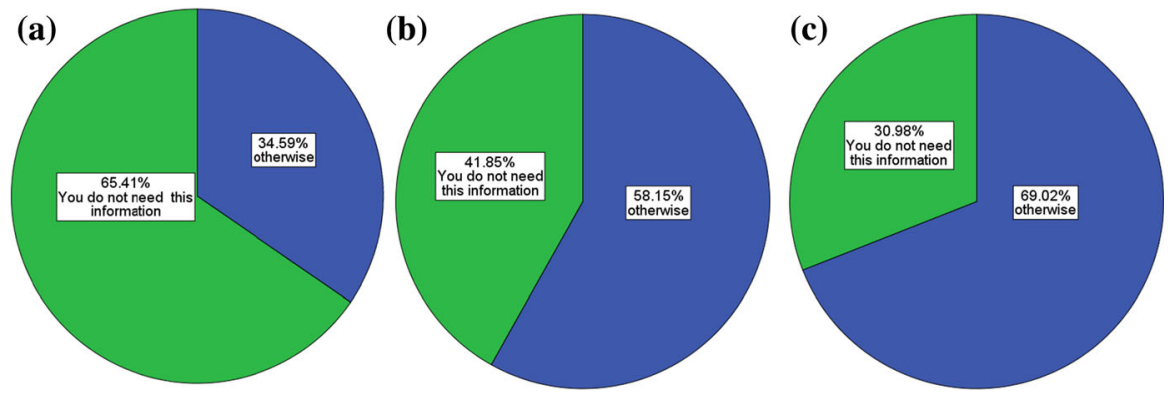

Fig. 5 a-c In future, if you no longer found 'best before' dates on other non-perishable foods, such as rice, pasta, coffee or tea, how would you respond? Responses for Western, Eastern and Mediterranean subsamples 
directly influence behaviour), the variance explained by the model is higher than when other methods, e.g., regression analysis, are used.

The model consists of two parts: the measurement model (which stipulates the relationships between the latent variables and their component indicators), and the structural model (which describes the causal relationships between the latent variables). The model is defined by the following system of three equations in matrix terms (Jöreskog and Sörbom 2007):

The structural equation model: $\eta=B \eta+\Gamma \xi+\zeta$

The measurement model for y: $y=\Lambda_{y} \eta+\varepsilon$

The measurement model for $\mathrm{x}: x=\Lambda_{x} \xi+\delta$

where $\eta$ is an $m^{*} 1$ random vector of endogenous latent variables; $\xi$ is an $n^{* 1} 1$ random vector of exogenous latent variables; $B$ is an $m^{*} m$ matrix of coefficients of the $\eta$ variables in the structural model; $\Gamma$ is an $\mathrm{m}^{*} \mathrm{n}$ matrix of coefficients of the $\xi$ variables in the structural model; $\zeta$ is an $\mathrm{m}^{*} 1$ vector of equation errors (random disturbances) in the structural model; $y$ is a $\mathrm{p}^{*} 1$ vector of endogenous variables; $\mathrm{x}$ is a $\mathrm{q}^{*} 1$ vector of predictors or exogenous variables; $\Lambda_{y}$ is a $\mathrm{p}^{*} \mathrm{~m}$ matrix of coefficients of the regression of $\mathrm{y}$ on $\eta ; \Lambda_{y}$ is a $\mathrm{q}^{*} \mathrm{n}$ matrix of coefficients of the regression of $\mathrm{x}$ on $\xi$; $\varepsilon$ is a $\mathrm{p}^{*} 1$ vector of measurement errors in $\mathrm{y}$; and $\delta$ is a $\mathrm{q}^{*} 1$ vector of measurement errors in $\mathrm{x}$.

The models were estimated using the Diagonally Weighted Least Squares (DWLS) method and the statistical package Lisrel 8.80 (Jöreskog and Sörbom 2007). We combine Prelis to calculate the asymptotic covariance matrix (Muthén 1984; Bollen 1989) and Lisrel to compute test statistics for the estimation of the significance of causal relationships (Jöreskog and Sörbom 2007). The DWLS estimation method is consistent with the types of variables included in the model (ordinal and categorical) and the deviation from normality in these variables (Finney and DiStefano 2006). The models were validated using absolute (root mean square error of approximation and goodness of fit index), incremental (adjusted goodness of fit index, non-normed fit index, normed fit index, relative fit index, comparative fit index and incremental fit index) and parsimonious (normed Chi square) goodness of fit (GoF) indicators (Hair et al. 2006). An acceptable level of overall goodness-of-fit does not guarantee that all constructs meet the requirements for the measurement and structural models. The validity of the SEM was assessed in a two-step procedure: the measurement model and the structural model. Model selection was performed through a nested model approach, in which the number of constructs and indicators remained constant, but the number of estimated relationships was changed iteratively.

\section{Results and discussion}

As mentioned in the method description section, the first step of the analysis consisted of a measurement model where the indicators (11) presented in Table 1 form the latent variables (7). The main parameters to test for the robustness of the 
Table 2 Goodness of fit indicators

\begin{tabular}{llllll}
\hline \multirow{2}{*}{ GoF indicators } & \multicolumn{3}{l}{ Estimated value } & \multicolumn{3}{c}{ Recommended value } \\
\cline { 2 - 4 } & West & East & Med & \\
\hline Root Mean Square Error of Approximation (RMSEA) & 0.033 & 0.032 & 0.021 & $0.00-0.10$ \\
Goodness of Fit Index (GFI) & 1 & 1 & 1 & $0.90-1.00$ \\
Normed Fit Index (NFI) & 0.98 & 0.98 & 0.99 & $0.90-1.00$ \\
Non-Normed Fit Index (NNFI) & 0.97 & 0.97 & 0.99 & $0.90-1.00$ \\
Comparative Fit Index (CFI) & 0.98 & 0.98 & 0.99 & $0.90-1.00$ \\
Incremental Fit Index (IFI) & 0.98 & 0.98 & 0.99 & $0.90-1.00$ \\
Relative Fit Index (RFI) & 0.97 & 0.97 & 0.98 & $0.90-1.00$ \\
Adjusted Goodness of Fit Index (AGFI) & 0.99 & 0.99 & 1 & $0.90-1.00$ \\
Standardized Root Mean Square Residual (SRMR) & 0.029 & 0.033 & 0.024 & $0.00-0.10$ \\
\hline
\end{tabular}

constructs, convergent validity and internal consistency (composite reliability, internal consistency reliability, extracted validity and discriminant validity) resulted in acceptable values for all constructs following Hair et al. (2006). In addition, the model meets the wider acceptance goodness-of-fit standards for the confirmatory model. Results of the measurement model are not reported due to length limitations.

The second step of the analysis consisted of the structural equation model. Instead of performing a multi-country analysis for the structural model, we grouped the 28 countries in the aforementioned three groups and then estimated SEMs for each group. The model explains 18, 15 and respectively $10 \%$ of the variance in the behaviour associated to date labelling evaluation in the three models. The model has excellent fit according to the measures of absolute, incremental and parsimonious fit (Hair et al. 2006). The main goodness-of-fit (GoF) indicators (estimated and recommended values) for the estimated model are presented in Table 2.

Additional testing of the appropriateness of the models was achieved by comparing each of the estimated models with three other models that acted as alternative explanations to the proposed models in a competing-model strategy using a nested model approach. The results across all types of goodness-of-fit measures favoured the estimated model in most cases. Therefore, the accuracy of the proposed models was confirmed and the competing models were discarded.

After assessing the overall models and aspects of the measurement models, the standardised structural coefficients were examined for both empirical and theoretical implications. Table 3 presents the standardised total effects between the latent variables in the model. All relationships in the three models are statistically significant.

The path diagrams for the estimated SEM models are presented in Fig. 6.

The results support the research hypotheses in the three models. Date label understanding has a negative impact on behaviour explaining a consistent fifth of the variance in the three models. Its effect on behaviour is direct and indirect through the frequency of date label checking, with which it has a significant positive 
Table 3 Standardised total (direct and indirect) effects

\begin{tabular}{llll}
\hline & \multicolumn{2}{l}{ Total standardised effects on food waste behaviour (behav) } \\
\cline { 2 - 4 } & West & East & Med \\
\hline Age & $-0.14^{* *}$ & $0.05^{*}$ & $-0.05^{* *}$ \\
Educ & $0.10^{* *}$ & $-0.07^{*}$ & \\
Occup & $0.01^{*}$ & $0.01^{*}$ & $0.09^{*}$ \\
Help & $-0.17^{* * *}$ & $-0.24^{* * *}$ & $0.06^{*}$ \\
Label & $-0.20^{* * *}$ & $-0.20^{* * *}$ & $-0.20^{* *}$ \\
Behavfr & $-0.29^{* * *}$ & $-0.23^{* * *}$ & $-0.22^{* * *}$ \\
R-square & 0.18 & 0.15 & 0.10 \\
Valid N & 9656 & 9752 & 4535 \\
\hline
\end{tabular}

The latent variable scores and observational residuals depend on the unit of measurement in the observed variables. As some of these units are the result of subjective scaling of the observed variables, the observational residuals were standardised (rescaled such that they have zero means and unit standard deviations in the sample) (Jöreskog and Sörbom 2007). Total effects represent how much a one-unit change in an independent variable will change the expected value of a dependent variable

*Statistically significant at 0.1 level; **statistically significant at 0.05 level; ***statistically significant at 0.01 level

relationship. The findings might indicate that consumers with a higher level of date label understanding are more likely to make regular use of date labels and less willing to consume foods without 'best before' dates or foods outside the period of time during which they must be used after opening. While the first relationship is as expected, it is less clear why consumers who understand the meaning of 'best before' labels are reluctant to disregard the absence of these labels on foods. This may be explained through the composition of the behavioural construct, which also includes an indicator with food safety implications (consumption of products which must be used within a certain number of days after opening and are past that).

Frequency of date label checking has a strong significant negative effect on behaviour explaining between a fifth and almost a third of the variance in the three models. This might indicate that consumers checking date labels regularly are less willing to consume food products which are not date-marked.

The perceived need for clearer information associated to date labelling has a significant effect on behaviour explaining up to a quarter of the variance and showing a large difference in effect magnitude and sign between the three models. Its impact on behaviour is direct and indirect through date label understanding and frequency of date label checking. The findings suggest that people with a stronger need for clearer labelling information are in the habit of checking date labels and are more likely to understand the limitations of the current date labelling. The need for information to build stronger behavioural control leads to better interpretation of labels and lower food waste. The different relationship sign in the three models requires further investigation.

As regards socio-demographics, with the exception of education, which does not influence behaviour in the Mediterranean model, all variables have significant effects on behaviour, albeit of very different magnitude between the three models. 

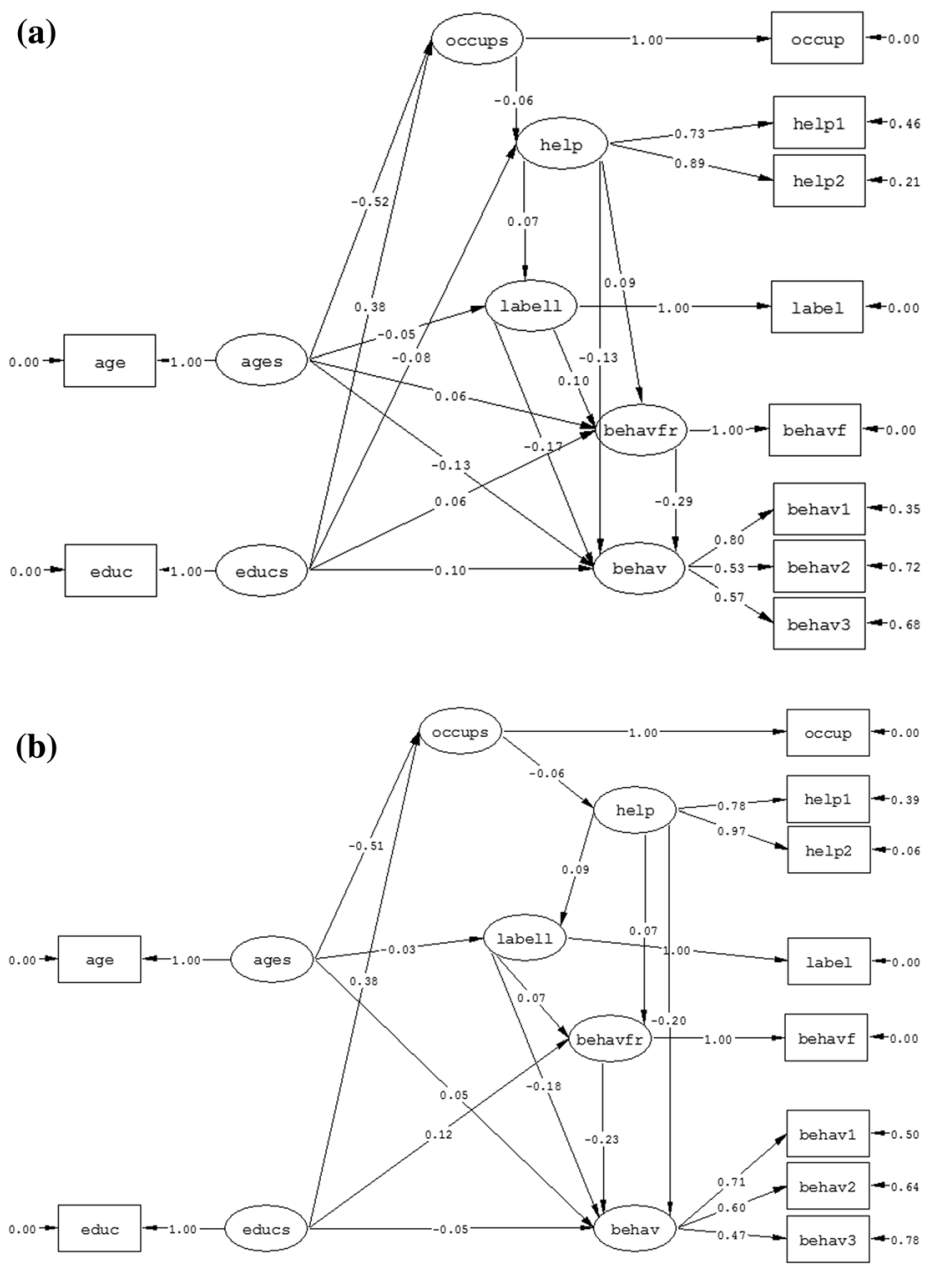

(c)

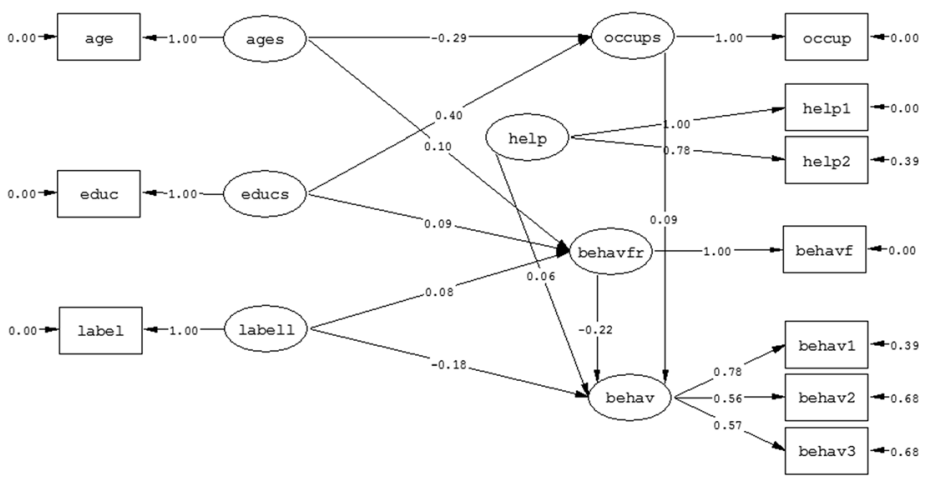

Fig. 6 a-c SEM path diagrams (direct effects—standardised solution) for West, East and Med models 
Compared to the other influences on behaviour described above, socio-demographic variables show low effects on behaviour with the exception of age and education in the West model. The effect of age on behaviour is direct and indirect through date label understanding and frequency of date label checking. This might suggest that younger consumers have a better understanding of date marking, while older consumers are more likely to check date labels more frequently. The relationship between age and behaviour in West and Mediterranean models suggests that younger people are more likely to carry out assessments of date labels leading to behaviours associated with lower food waste. However the relationship has a different sign in the East model, which may suggest lower food waste associated with older people, which could be explained through income aspects. The sign difference between West and East models also occurs for the effect of education on behaviour and the same income-related reasoning might apply.

The effect of occupation on behaviour is direct and indirect through the perceived need for clearer date labelling information. This might suggest that consumers with better occupational status (and implicitly higher income/socio-economic group) are more likely to perceive the limitations of the current date marking and require clearer information, and are also more likely to exhibit behaviours associated with lower food waste.

A limitation of this research is the low variance explained by the models, which is due to the fact that many established influences (e.g., food safety perceptions) on the specific behaviours analysed here were missing from the survey questionnaire.

\section{Conclusions}

Household food consumption has been regarded as a key point in food waste generation and significant efforts by e.g., Food and Agricultural Organization of the United Nations and the European Commission have been directed to assist consumers in reducing food waste. However, there is more to be done as the majority of the current food waste mitigation initiatives together with the EU legislation tackle the food waste conundrum from a waste management perspective.

Date labelling influences the selection of food at the point of purchase and its subsequent consumption and most likely has a strong effect on consumers' decision of what to eat or throw out. Our research analysed the influence of date label understanding among other factors (socio-demographics, date label understanding, need for clearer date labelling information and frequency of date label checking) on a number of specific behaviours associated with lower food waste.

Our results suggest that the frequency of checking and understanding of date labels are the main determinants of behaviour in all regions analysed (Western, Eastern and Mediterranean Europe). However, differences between the three EU regions emerge in terms of the importance of date labelling for consumption decisions. Such differences may stem from the institutional, regulatory and policy framework, public information campaigns and food culture in these countries.

Building on the limitations of this study, future work should incorporate the role of food safety and risk perceptions, which would increase the variance explained in 
the analysis. Consumers have become less knowledgeable of the characteristics associated to safe and good quality food and rely increasingly on food label instructions, which may indicate insufficient control on food safety matters.

The positive relationship found between the stated level of date label understanding and the perceived need for further information on date labelling might indicate the need for changes in date labelling and for targeted communication strategies consistent with existing policy initiatives across the European Union. This is consistent with the current views of EU policy makers and national institutions, e.g., WRAP, which have proposed new guidance on the application of date labels including a flexible implementation of the date of minimum durability while maintaining strict food safety principles (WRAP 2017).

Acknowledgements We thank the Scottish Government who funded this research as part of the Rural Affairs, Food and the Environment (RAFE) Strategic Research Programme 2016-2021 Theme 3 RD3.1.4 'Preventing food waste'.

\section{Compliance with ethical standards}

Conflict of interest The authors declare that they have no conflict of interest.

Open Access This article is distributed under the terms of the Creative Commons Attribution 4.0 International License (http://creativecommons.org/licenses/by/4.0/), which permits unrestricted use, distribution, and reproduction in any medium, provided you give appropriate credit to the original author(s) and the source, provide a link to the Creative Commons license, and indicate if changes were made.

\section{References}

Ajzen I, Madden TJ (1986) Prediction of goal-directed behavior: attitudes, intentions, and perceived behavioral control. J Exp Soc Psychol 22(5):453-474

Broad Leib E, Rice C, Neff R, Spiker M, Schklair A, Greenberg S (2016) Consumer perceptions of date labels: National Survey. Harvard Food Law and Policy Clinic. USA, checked on 9/21/2016

Bollen KA (1989) Structural equations with latent variables. Wiley, New York

Buzby JC, Wells HF, Hyman J (2016) The estimated amount, value, and calories of postharvest food losses at the retail and consumer levels in the United States. United States Department of Agriculture, Economic (Economic Information Bulletin Number 121), checked on 9/30/2016

European Commission (2011) Regulation (EU) No 1169/2011 of the European Parliament and of the Council of 25 October 2011 on the provision of food information to consumers, amending Regulations (EC) No 1924/2006 and (EC) No 1925/2006 of the European Parliament and of the Council, and repealing Commission Directive 87/250/EEC, Council Directive 90/496/EEC, Commission Directive 1999/10/EC, Directive 2000/13/EC of the European Parliament and of the Council, Commission Directives 2002/67/EC and 2008/5/EC and Commission Regulation (EC) No 608/2004Text with EEA relevance, checked on 9/30/2016

European Commission (2015) Flash eurobarometer 425: food waste and date marking. European Commission, Brussels

European Environment Agency (2015) Communication, environment and behaviour. A scoping study on the links between public communication, environment policy implementation and behavioural science. EEA, Copenhagen. Doi:10.2800/062336, checked on 7/11/2016

Evans D (2011) Blaming the consumer-once again. The social and material contexts of everyday food waste practices in some English households. Crit Public Health 21(4):429-440. doi:10.1080/ 09581596.2011 .608797 
Evans D (2012) Beyond the throwaway society. ordinary domestic practice and a sociological approach to household food waste. Sociology 46(1):41-56. doi:10.1177/0038038511416150

FSA (Food Standards Agency) (2016) Understanding NI consumer needs around food labelling. Availableonline at http://www.food.gov.uk/northern-ireland/news-updates/news/2016/15424/ understanding-ni-consumer-needs-around-food-labelling

Finney SJ, DiStefano C (2006) Non-normal and categorical data in structural equation modeling. In: Hancock GR, Mueller RO (eds) Structural equation modeling: a second course. Information Age Publishing, Greenwich, pp 269-314

Grunert KG, Fernandez-Celemin L, Wills JM, S Storcksdieck Genannt Bonsmann, Nureeva L (2010) Use and understanding of nutrition information on food labels in six European countries. In Zeitschrift fur Gesundheitswissenschaften. J Public Health 18(3):261-277. doi:10.1007/s10389-009-0307-0

Gustavsson J, Cederberg C, Sonesson U (2011) Global food losses and food waste. Extent, causes and prevention; study conducted for the International Congress Save Food! at Interpack 2011, [16-17 May], Düsseldorf, Germany. Rome: Food and Agriculture Organization of the United Nations, checked on 9/30/2016

Hair JF, Black W, Babin B, Anderson RE, Tatham RL (2006) Multivariate data analysis, 6th edn. Pearson Prentice Hall, Upper Saddle River

High Level Panel of Experts (HLPE) (2014) Food losses and waste in the context of sustainable food systems: a report by the High Level Panel of Experts on Food Security and Nutrition of the Committee on World Food Security. FAO, Rome, checked on 9/30/2016

Jöreskog KG, Sörbom D (2007) LISREL8.80: structural equation modeling with the SIMPLIS command language. Scientific Software International, Chicago

Jörissen J, Priefer C, Bräutigam K-R (2015) Food waste generation at household level: results of a survey among employees of two European research centers in Italy and Germany. Sustainability 2015(7):2695-2715

Kaiser FG, Fuhrer U (2003) Ecological behavior's dependency on different forms of knowledge. Appl Psychol 52(4):598-613. doi:10.1111/1464-0597.00153

Mallinson LJ, Russell JM, Barker ME (2016) Attitudes and behaviour towards convenience food and food waste in the United Kingdom. Appetite 103:17-28

Mena C, Terry LA, Williams A, Ellram L (2014) Causes of waste across multi-tier supply networks. Cases in the UK food sector. Int J Prod Econ 152:144-158. doi:10.1016/j.ijpe.2014.03.012

Meysenburg R, Albrecht JA, Litchfield R, Ritter-Gooder PK (2014) Food safety knowledge, practices and beliefs of primary food preparers in families with young children. A mixed methods study. Appetite 73:121-131. doi:10.1016/j.appet.2013.10.015

Muthén B (1984) A general structural equation model with dichotomous, ordered categorical, and continuous latent variable indicators. Psychometrika 49:115-132

NRDC (Natural Resources Defense Council) (2013). The dating game: how confusing food date labels leadto food waste in America. Available online at https://www.nrdc.org/sites/default/files/datinggame-report.pdf

Parfitt J, Barthel M, Macnaughton S (2010) Food waste within food supply chains: quantification and potential for change to 2050. Philos Trans R Soc Lond B Biol Sci 365(1554):3065-3081. doi:10. 1098/rstb.2010.0126

Peschel AO, Grebitus C, Steiner B, Veeman M (2016) How does consumer knowledge affect environmentally sustainable choices? Evidence from a cross-country latent class analysis of food labels. Appetite. doi:10.1016/j.appet.2016.02.162

Priefer C, Jörissen J, Bräutigam K-R (2016) Food waste prevention in Europe-a cause-driven approach to identify the most relevant leverage points for action. Resour Conserv Recycl 109:155-165. doi:10.1016/j.resconrec.2016.03.004

Quested TE, Marsh E, Stunell D, Parry AD (2013) Spaghetti soup. The complex world of food waste behaviours. Resour Conserv Recycl 79:43-51. doi:10.1016/j.resconrec.2013.04.011

Rahelu K (2009) Date labelling on food. Nutr Bull 34(4):388-390. doi:10.1111/j.1467-3010.2009.01779. $\mathrm{X}$

Redman E, Redman A (2014) Transforming sustainable food and waste behaviors by realigning domains of knowledge in our education system. J Clean Prod 64:147-157. doi:10.1016/j.jclepro.2013.09.016

Sanlier N (2009) The knowledge and practice of food safety by young and adult consumers. Food Control 20(2009):538-542

Stenmarck Å, Jensen C, Quested T (2016) Estimates of European food waste levels. FUSIONS EU, checked on 9/30/2016 
TNS European Behaviour Studies Consortium (2014) Impact of food information on consumers' decision making, checked on 9/30/2016

Van Boxstael S, Devlieghere F, Berkvens D, Vermeulen A, Uyttendaele M (2014) Understanding and attitude regarding the shelf life labels and dates on pre-packed food products by Belgian consumers. Food Control 37:85-92. doi:10.1016/j.foodcont.2013.08.043

Van Garde SJ, Woodburn MJ (1987) Food discard practices of householders. J Am Dietetic Assoc 87(3):322-329

Visschers VHM, Wickli N, Siegrist M (2016) Sorting out food waste behaviour: a survey on the motivators and barriers of self-reported amounts of food waste in households. J Environ Psychol 45:66-78. doi:10.1016/j.jenvp.2015.11.007

Wardle J, Parmenter K, Waller J (2000) Dietary restraint and self-reported meal sizes: diary studies with differentially informed consent. Appetite 34:269-275. doi:10.1006/appe.2000.0314

Watson MT, Meah A (2012) Food and waste: negotiating conflicting social anxieties into the practices ofprovisioning. Sociol Rev Monogr S2(60):102-120

Worsley A (2002) Nutrition knowledge and food consumption: can nutrition knowledge change food behaviour? Asia Pac J Clin Nutr 11(2):S579-S585. doi:10.1111/1467-9558.00163

WRAP (2007) Food behaviour consumer research: quantitative phase. Available online at http://www. wrap.org.uk/content/food-behaviour-consumer-research-quantitative-phase

WRAP (2011) Consumer insight: date labels and storage guidance. Waste and Resources Action Programme, checked on 7/13/2016

WRAP (2013a) Household food and drink waste in the United Kingdom 2012. WRAP, checked on 9/21/ 2016

WRAP (2013b) The milk model: simulating food waste in the home, checked on 9/21/2016

WRAP (2014) Household food and drink waste: a people focus. Available online at http://www.wrap.org. uk/content/household-food-drink-waste-people-focus

WRAP (2015) Reducing food waste by extending product life. WRAP. http://www.wrap.org.uk/content/ reducing-food-waste-extending-product-life, checked on 7/11/2016

WRAP (2017) Guidance on application of date labels and related advice. Draft for consultation. http:// www.wrap.org.uk/sites/files/wrap/Draft_Guidance_on_application_of_date_marks_and_related_ advice.pdf 